Original Research Article

\title{
A study of utilization pattern of drugs in HIV positive patients at antiretroviral therapy centre of a tertiary care teaching hospital
}

\author{
Shailesh P. Parmar ${ }^{1}$, Jay Kumar Sharma ${ }^{2 *}$, Hiren R. Trivedi ${ }^{1}$
}

${ }^{1}$ Department of Pharmacology, M.P. Shah Govt. Medical College, Jamnagar, Gujarat, India

${ }^{2}$ Regional Medical Advisor, Novo Nordisk India Pvt Ltd, EPIP Area, Whitefield, Bangalore, India

Received: 29 January 2018 Accepted: 03 February 2018

*Correspondence to:

Dr. Jay Kumar Sharma, Email: jaykumarjaks@ gmail.com

Copyright: (C) the author(s), publisher and licensee Medip Academy. This is an openaccess article distributed under the terms of the Creative Commons Attribution NonCommercial License, which permits unrestricted noncommercial use, distribution, and reproduction in any medium, provided the original work is properly cited.

\begin{abstract}
Background: Infection with human immunodeficiency virus (HIV) and subsequent acquired immunodeficiency syndrome (AIDS) continues to be a major public health problem. Treatment and therapeutic guidelines have evolved over a period of time. Drug utilization study helps to evaluate changing pattern of drug use, compliance with national guidelines and rational use of drugs.

Methods: Authors conducted observational, non interventional, descriptive study in outdoor HIV positive patients for one year. We have analysed collected data using descriptive statistics to determine drug use indicators and utilization pattern of drugs.

Results: Study showed that average number of drugs per encounter was 3.96. The most commonly prescribed antiretroviral therapy (ART) regime was combination of zidovudine, lamivudine with nevirapine (51.92\%). Among antiretroviral drugs prescribed, nucleoside reverse transcriptase inhibitors $(49.45 \%)$ were the most common drug subclass and lamivudine $(33.33 \%)$ was the most common antiretroviral drug. Second most common medication class was antibacterial agents $(18.77 \%)$ and co-trimoxazole $(10.11 \%)$ was the most common antibacterial agent. The third most commonly prescribed drug class was vitamins namely folic acid and multivitamins $(2.63 \%)$. Percentage of encounters with an antibiotic prescribed was $41.46 \%$. Tuberculosis was the most common opportunistic infection. In $90.05 \%$ of encounters with ART prescriptions, adherence was more than $95 \%$.

Conclusions: Overall the results suggest that the prescribing pattern to be in accordance with national guidelines and reflect changing patterns of drug usage in HIV positive patients in World. Drug use indicators reflect rational approach to prescribing pattern.
\end{abstract}

Keywords: Antiretroviral therapy, Drug utilization study, HIV/AIDS

\section{INTRODUCTION}

Infection with human immunodeficiency virus (HIV) continues to be a major public health issue, having claimed more than 35 million lives so far. Nearby 36.7 million people were living with HIV and 1.8 million people became newly infected in 2016 globally. ${ }^{1} \mathrm{HIV}$ is the initial causative agent but most of the morbidity and mortality in acquired immunodeficiency syndrome (AIDS) cases result from opportunistic infections. Treatment options and therapeutic guidelines have evolved since availability of highly active antiretroviral treatment became the standard of HIV treatment. Various drugs available for HIV treatment belongs to classes of nucleoside reverse transcriptase inhibitors (NRTIs), non-nucleoside reverse transcriptase inhibitors (NNRTIs), protease inhibitors (PIs), fusion inhibitors, entry inhibitors, CCR5 co-receptor antagonist and HIV integrase strand transfer inhibitors. ${ }^{2}$ In India, people living with HIV were estimated at 21.17 
lakhs in $2015 .{ }^{3}$ National AIDS control programme in India provides various means of prevention, care and treatment through antiretroviral therapy (ART) centres. Adopting changing trends in pharmacotherapy of HIV/AIDS in the world and rational use of drugs are some of the measures to treat and contain HIV/AIDS more effectively. Drug utilization studies are powerful exploratory tools to ascertain role of drugs in society. These studies help to evaluate changing pattern of drug use, compliance with national guidelines and rational use of drugs. ${ }^{4}$

\section{METHODS}

This observational, non interventional, descriptive study was carried out after approval from institutional ethics committee of the institute. Authors used a sample consisting 1268 encounters. Duration of study was from March 2015 to February 2016. In this study, authors included HIV positive patients of both sex including pregnant and lactating mother treated as outdoor patients at ART centre of the institute. The diagnosis and line of treatment to be given was decided by the physician in charge of the ART centre. Written informed consent was taken from patients fulfilling study criteria. After interview of patient and review of prescription, data regarding clinical status, opportunistic infections, drugs prescribed etc. were recorded in case record forms. Adherence was determined by asking patient about missed doses and by verifying empty package of ART drugs. The level of adherence was recorded $>95 \%$ if less than 3 doses missed, $80-95 \%$ if $3-12$ doses missed and $<80 \%$ if more than 12 doses missed. ${ }^{5}$ The data collected was analysed with the help of MS excel using descriptive statistics to determine drug use indicators and utilization pattern of drugs. ${ }^{5}$

\section{RESULTS}

Authors have analyzed data of 1268 prescriptions from 255 patients. Majority of patients were from 20 to 40 years age group (57.25\%) and male (61.57\%). $64.71 \%$ were started antiretroviral therapy in less than one year duration after diagnosis of HIV infection. Table 1 shows summery of demographic characteristics of patients.

Table 1: Demographic characteristics of patients.

\begin{tabular}{|ll|}
\hline Characteristics & No. of patients $(\mathbf{n}=\mathbf{2 5 5})$ \\
\hline Age (years) & $6-85$ years \\
\hline Range & $38.85 \pm 11.22$ years \\
\hline Mean age \pm SD & $157(61.57 \%)$ \\
\hline Sex & $98(38.43 \%)$ \\
\hline Male & \\
\hline Female & $33(12.94 \%)$ \\
\hline $\begin{array}{l}\text { Time between diagnosis of HIV infection and initiation } \\
\text { of ART }\end{array}$ & $165(64.71 \%)$ \\
\hline On pre ART management & $37(14.51 \%)$ \\
\hline$<1$ year & $20(7.84 \%)$ \\
\hline $1-4$ years & \\
\hline$>4$ years & $215(84.31 \%)$ \\
\hline Based on PI in regime & $7(2.75 \%)$ \\
\hline Non-PI based regime & $33(12.94 \%)$ \\
\hline PI based regimes & $175(68.63 \%)$ \\
\hline Not receiving ART regimes & $47(18.43 \%)$ \\
\hline Treatment duration & \\
\hline$<5$ years & \\
\hline$>5$ years &
\end{tabular}

The medication class most commonly prescribed was antiretroviral agents $(74.18 \%)$. Prescribing pattern of subclass of antiretroviral agents was nucleoside reverse transcriptase inhibitors $(49.45 \%)$ followed by non nucleoside reverse transcriptase inhibitors $(23.86 \%)$ and protease inhibitors $(0.87 \%)$ (Table 2$)$. The most commonly prescribed antiretroviral agent was lamivudine (33.33\%), followed by zidovudine $(20.09 \%)$, nevirapine $(18.23 \%)$. Ritonavir boosted atazanavir $(1 \%)$ was preferred protease inhibitor (Figure 1).

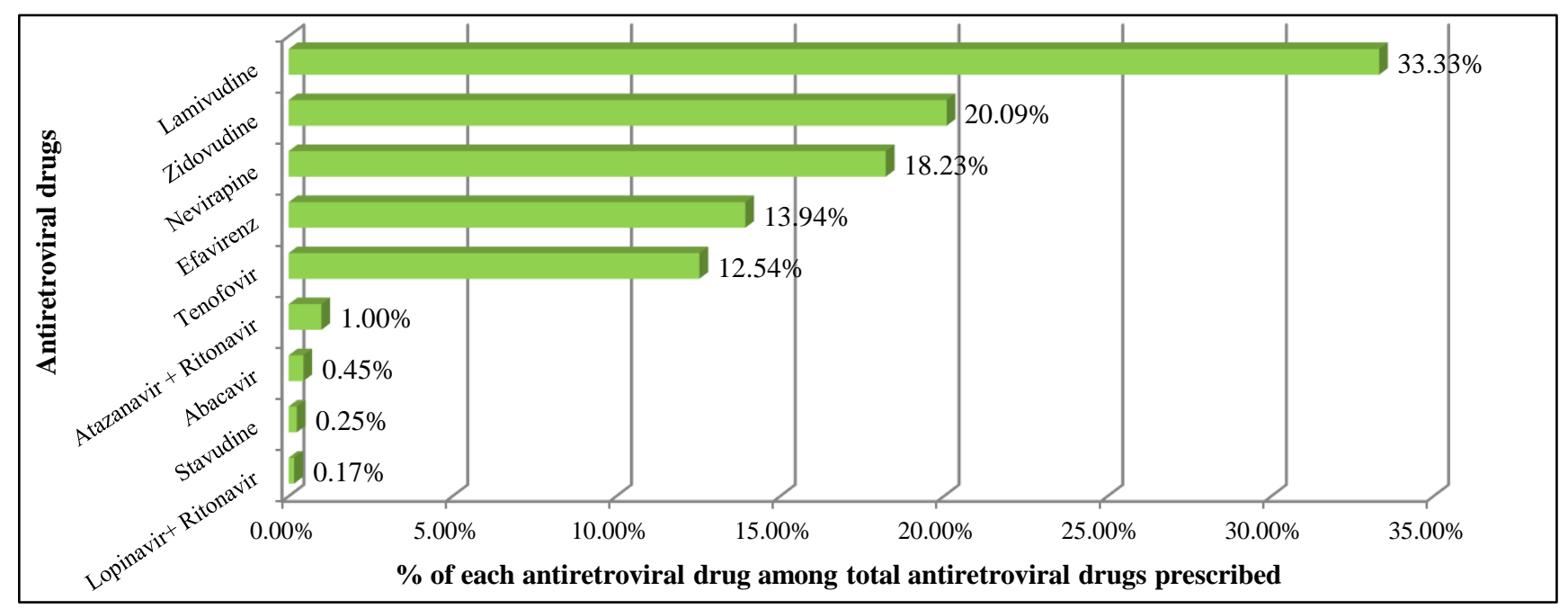

Figure 1: Percentage of each antiretroviral drug among total antiretroviral drugs prescribed. 
Table 2: Prescribing pattern of drugs used in HIV positive patients.

\begin{tabular}{|c|c|c|}
\hline Drugs & No. of drugs prescribed ( $n=4837)$ & Percentage \\
\hline 1. Antiretroviral agents & 3588 & $74.18 \%$ \\
\hline a) Nucleoside reverse transcriptase inhibitors & 2392 & $49.45 \%$ \\
\hline Zidovudine & 721 & $14.91 \%$ \\
\hline Stavudine & 9 & $0.19 \%$ \\
\hline Lamivudine & 1196 & $24.73 \%$ \\
\hline Abacavir & 16 & $0.33 \%$ \\
\hline Tenofovir & 450 & $9.30 \%$ \\
\hline b) Non-nucleoside reverse transcriptase inhibitors & 1154 & $23.86 \%$ \\
\hline Nevirapine & 654 & $13.52 \%$ \\
\hline Efavirenz & 500 & $10.34 \%$ \\
\hline c) Protease inhibitors & 42 & $0.87 \%$ \\
\hline Atazanavir (ritonavir boosted) & 36 & $0.74 \%$ \\
\hline Lopinavir (ritonavir boosted) & 6 & $0.12 \%$ \\
\hline \multicolumn{3}{|l|}{ 2. Other antimicrobial agents } \\
\hline a) Antiviral drugs- Acyclovir & 1 & $0.02 \%$ \\
\hline b) Anti bacterial agents & 908 & $18.77 \%$ \\
\hline Antitubercular drugs & 393 & $8.12 \%$ \\
\hline Isoniazid & 89 & $1.84 \%$ \\
\hline Rifampicin & 89 & $1.84 \%$ \\
\hline Pyrazinamide & 89 & $1.84 \%$ \\
\hline Ethambutol & 89 & $1.84 \%$ \\
\hline Streptomycin & 37 & $0.76 \%$ \\
\hline Other antibacterial agents & 515 & $10.65 \%$ \\
\hline Co-trimoxazole & 489 & $10.11 \%$ \\
\hline Amoxicillin+ Clavulinic acid & 2 & $0.04 \%$ \\
\hline Cefixime & 6 & $0.12 \%$ \\
\hline Azithromycin & 13 & $0.27 \%$ \\
\hline Doxycycline & 4 & $0.08 \%$ \\
\hline Norfloxacin & 1 & $0.02 \%$ \\
\hline c) Antifungal agents & 22 & $0.45 \%$ \\
\hline Fluconazole & 9 & $0.19 \%$ \\
\hline Clotrimazole cream & 13 & $0.27 \%$ \\
\hline d) Antiprotozoal agents & 8 & $0.17 \%$ \\
\hline Metronidazole & 6 & $0.12 \%$ \\
\hline Chloroquine & 1 & $0.02 \%$ \\
\hline Nitazoxanide & 1 & $0.02 \%$ \\
\hline 3. Vitamins & 127 & $2.63 \%$ \\
\hline Inj. Neurobion & 2 & $0.04 \%$ \\
\hline Folic acid & 38 & $0.79 \%$ \\
\hline Multivitamins & 87 & $1.80 \%$ \\
\hline 4. Haematinics-Ferrous sulphate & 48 & $0.99 \%$ \\
\hline 5. Miscellaneous drugs & 135 & $2.79 \%$ \\
\hline
\end{tabular}

Combination of zidovudine, lamivudine with nevirapine $(51.92 \%)$ was the most commonly prescribed ART regime followed by tenofovir, lamivudine with efavirenz $(34.62 \%)$ and zidovudine, lamivudine with efavirenz $(7.11 \%)$.

Figure 2 shows prescribing pattern of ART regimes. Second most common medication class was antibacterial agents $(18.77 \%)$. The most common antibacterial agent used was co-trimoxazole $(10.11 \%)$, followed by antitubercular agents $(8.12 \%)$. The third most commonly prescribed drug class was vitamins namely folic acid and multivitamins $(2.63 \%)$ followed by haematinic drugs $(0.99 \%)$. Table 2 shows prescribing pattern of drugs. Miscellaneous drugs in Table 2 include paracetamol $(0.81 \%)$, cetrizine $(0.76 \%)$, famotidine $(0.58 \%)$, GBHC lotion $(0.08 \%)$, domperidone $(0.06 \%)$, albendazole 
$(0.06 \%)$, diclofenac $(0.04 \%)$, calcium $(0.29 \%)$, phenytoin

$(0.02 \%)$ atenolol (0.02\%), amlodipine (0.02\%),

deriphylline $(0.02 \%)$ and calamine lotion $(0.02 \%)$.

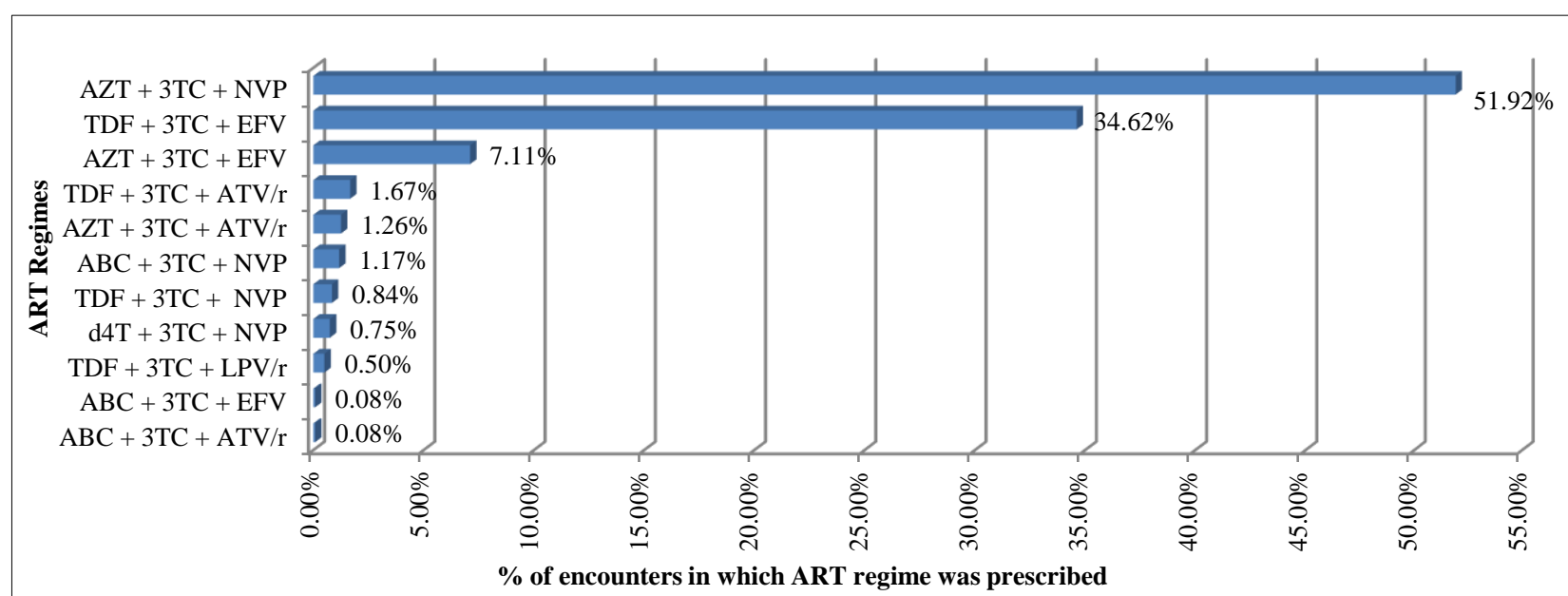

AZT- zidovudine, 3TC- lamivudine, TDF- tenofovir, ABC- abacavir, d4T- stavudine, NVP- nevirapine, EFV-efavirenz, ATV/r- ritonavir boosted atazanavir, LPV/r- ritonavir boosted lopinavir

Figure 2: Utilisation pattern of different ART regimens.

Table 3: Summary of drug use indicators.

\begin{tabular}{|ll|}
\hline indicators & $\begin{array}{c}\text { Indicator } \\
\text { statistics }\end{array}$ \\
\hline 1. Prescribing indicators & \\
\hline Average number of drugs prescribed & 3.96 \\
\hline $\begin{array}{l}\% \text { of encounters with an antibiotic } \\
\text { prescribed }\end{array}$ & $41.46 \%$ \\
\hline $\begin{array}{l}\% \text { of encounters with injections } \\
\text { prescribed }\end{array}$ & $0.81 \%$ \\
\hline$\%$ of drugs prescribed by generic name & $89.85 \%$ \\
\hline $\begin{array}{l}\% \text { of drugs prescribed from essential } \\
\text { medicine list }\end{array}$ & $90.91 \%$ \\
\hline 2. Patient care indicators & 12.11 \\
\hline Average consulting time (min) & 69.30 \\
\hline Average dispensing time (sec) & $94.11 \%$ \\
\hline$\%$ of drug dispensed & $92.94 \%$ \\
\hline Patient knowledge of correct dosage & \\
\hline 3. Facility indicators & Yes \\
\hline $\begin{array}{l}\text { Availability of essential medicine list or } \\
\text { formulary }\end{array}$ & $93.18 \%$ \\
\hline Key drugs available & \\
\hline
\end{tabular}

The average number of drugs per encounter was 3.96 in this study with maximum number of drugs prescribed in a prescription was 12 . Table 3 shows summary of drug use indicators. $^{5}$ In $90.05 \%$ of encounters with ART prescriptions, adherence was $>95 \%$.
In $8.61 \%$ and $0.5 \%$ of total encounters, adherence was 80 $95 \%$ and $<80 \%$ respectively. Tuberculosis was the most common opportunistic infection. Table 4 shows summary of opportunistic infections.

Table 4: Occurrences of opportunistic infections among HIV positive patients.

\begin{tabular}{|ll|}
\hline Opportunistic infections & Percentage \\
\hline Tuberculosis & $59.33 \%$ \\
\hline Upper Respiratory tract infections & $16.67 \%$ \\
\hline Skin infections & $1.33 \%$ \\
\hline Diarrhoea & $6.00 \%$ \\
\hline Sexual transmitted diseases & $2.00 \%$ \\
\hline Lower respiratory infections & $0.67 \%$ \\
\hline Urinary tract infection & $0.67 \%$ \\
\hline Fungal infections & $12.00 \%$ \\
\hline a) Candidiasis & $3.33 \%$ \\
\hline b) Tinea & $8.00 \%$ \\
\hline c) Actinomycosis & $0.67 \%$ \\
\hline Warts & $0.67 \%$ \\
\hline Scabies & $0.67 \%$ \\
\hline
\end{tabular}

\section{DISCUSSION}

Majority of patients in this study belonged to the age group of 20-40 years (mean age of 38.85 years). Higher prevalence among these economically productive and sexually active group is in consonance with other studies. ${ }^{6-9}$ Majority of patients were males (61.57\%) 
compared to females. Similar higher HIV seropositivity among male was seen in other studies. ${ }^{6-8}$

In thisstudy, $87.06 \%$ patients were receiving antiretroviral drugs and $12.94 \%$ were under pre ART management, who were not receiving antiretroviral drugs. In similar study by Jiyo et al, $48 \%$ patients were not receiving ART. ${ }^{6}$ Change in $\mathrm{CD}^{+}{ }^{+}$count criteria for initiation of ART in recent ART guideline by national AIDS control organization (NACO) can be the reason for less percentage of patients under pre ART management in this study compared to other study. In 2007 ART guidelines by NACO, CD4 ${ }^{+}$count criterion for initiation of ART was $<200$ cells $/ \mathrm{mm}^{3}$ for WHO clinical staging 1 and 2 . For WHO clinical staging 3, criterion was "consider initiating ART if $\mathrm{CD}^{+}$" count was $<350$ cells $/ \mathrm{mm}^{3}$ and start ART if count was $<200$ cells $/ \mathrm{mm}^{3}$." ${ }^{10}$ In 2013 guideline for ART by NACO, these criteria were changed to "start ART if CD4+ count $<350$ cells $/ \mathrm{mm}^{3}$ in patients with WHO clinical staging 1 or 2 and start ART irrespective of $\mathrm{CD}^{+}$count in patients with WHO staging 3 or $4 .{ }^{\prime \prime}$

In this study, majority of patients $(64.71 \%)$ were started antiretroviral therapy in less than one year duration after diagnosis of HIV infection. Mean duration between diagnosis of HIV infection and initiation of ART was 12.91 months. The findings are in consonance with other study. ${ }^{9}$ Timely ART initiation decreases morbidity and mortality in HIV positive patients. Follow-up after diagnosis of HIV infection, pre ART management and counselling make timely ART initiation possible.

Before the availability of antiretroviral therapy, median survival after diagnosis of AIDS was 12 to 18 months. ${ }^{11}$ This has changed dramatically since the advent of ART which has significantly decreased mortality and morbidity. In this study, majority of patients were receiving ART since less than 5 years duration. The finding is in consonance with other studies. ${ }^{6,12}$

Majority of patients $(84.31 \%)$ were on non PI based regime. This finding is in accordance with other studies. ${ }^{6,9}$ As per the ART guideline 2013 by NACO, PI-based regime is to be used as second line regime. ${ }^{5}$ PI-based regimes can pose challenges, such as a more complex dosing schedules, drug interactions, toxicities and increase in cost. ${ }^{2,5}$

In this study, the most common ART regime prescribed was the combination of zidovudine with lamivudine and nevirapine $(51.92 \%)$ followed by tenofovir with lamivudine and efavirenz $(34.62 \%)$, zidovudine with lamivudine and efavirenz $(7.11 \%)$. The above findings are in accordance with national guidelines for antiretroviral therapy 2013 by NACO, which recommends zidovudine with lamivudine and nevirapine as the first choice. ${ }^{5}$ The study conducted by Hasabi et al, showed similar findings. ${ }^{8}$ This study finding differs from other previous studies in which stavudine based regimes were among commonly prescribed regime. ${ }^{6,7}$ Since 2006, the World Health
Organization has encouraged countries to transition away from first-line ART containing stavudine, due to well recognized toxicities including lactic acidosis, lipodystrophy, and peripheral neuropathy. The ART guidelines 2010 by WHO solidified this recommendation, stating that "countries should take steps to progressively reduce the use of stavudine in first-line regimes." In lieu of stavudine, the WHO and other expert bodies recommended first-line adult ART that utilized an NRTI backbone of either zidovudine or tenofovir. ${ }^{13-15}$ These recommendations were adopted in national ART guideline 2013 by NACO. ${ }^{5}$ Thus this study showed decrease in usage of stavudine based regimes compared to previous studies.

In this study, usage of tenofovir based regimes was higher compared to previous studies. ${ }^{6,7}$ These findings are also in consonance with recommendation by guidelines and changing trend of usage of nucleoside reverse transcriptase inhibitors in other countries. ${ }^{14,16}$ The study by Oreagba et al, showed prescribing pattern of zidovudine + lamivudine + nevirapine $(53.71 \%)$ followed by tenofovir + emtricitabine + efavirenz $(15.78 \%)$ and zidovudine + lamivudine + efavirenz $(7.34 \%) .{ }^{17}$ This difference in prescribing rates of various regimes may be due to difference between the guidelines for antiretroviral therapy in various countries.

In this study, the drug class most commonly prescribed to HIV positive patients was antiretroviral agents $(74.18 \%)$, with nucleoside reverse transcriptase inhibitors $(49.45 \%)$, non-nucleoside reverse transcriptase inhibitors $(23.86 \%)$ and protease inhibitors $(0.87 \%)$. The drug classes most commonly prescribed to HIV positive patients were antiretroviral agents (39\%), with nucleoside reverse transcriptase inhibitors $(25.96 \%)$, non-nucleoside reverse transcriptase inhibitors $(12.14 \%)$ and protease inhibitors $(0.90 \%)$ in the study conducted by Jiyo et al. ${ }^{6}$ Change in the criteria for initiation of antiretroviral therapy in HIV positive patients explains higher proportion of antiretroviral drugs usage in this study. ${ }^{5,10}$

Highly active ART (HAART) includes use of a treatment combination, which contains at least one protease inhibitor or non nucleoside reverse transcriptase inhibitor or three or more nucleoside reverse transcriptase inhibitors. Nucleoside reverse transcriptase inhibitors remain the backbone of ART as shown by various studies. ${ }^{14,16}$ Thus nucleoside reverse transcriptase inhibitors were the most commonly prescribed antiretroviral drugs in this study. Usage of protease inhibitors or non nucleoside reverse transcriptase inhibitors in HAART differs in various countries and at various time points. ${ }^{16,18}$ Protease inhibitor based regimes cause more intolerance/adverse effects and non nucleoside reverse transcriptase inhibitor based regimes has higher rate of immunologic failure. ${ }^{19}$ Because of side effects, dosage and drug interactions, non nucleoside reverse transcriptase inhibitors are preferable to protease inhibitors in HAART combinations. As per world health organization recommendation, first line ART should be one non nucleoside reverse transcriptase 
inhibitor with two nucleoside reverse transcriptase inhibitors. These recommendations were adopted in national guidelines for ART 2013. ${ }^{5}$ Thus non nucleoside reverse transcriptase inhibitors remained second most commonly prescribed antiretroviral drugs in this study followed by protease inhibitors.

Like in the other studies, among antiretroviral agents, the most commonly prescribed nucleoside reverse transcriptase inhibitor and non nucleoside reverse transcriptase inhibitor were lamivudine $(33.33 \%)$ and nevirapine (18.23\%) respectively. ${ }^{6,20}$ Among nucleoside reverse transcriptase inhibitors, lamivudine was the most frequently prescribed drug followed by zidovudine in the ART regimes. These findings are in consonance with findings of other studies..$^{6,7,19}$ Higher usage of lamivudine can be due to its good safety profile and its ability to restore susceptibility to zidovudine and tenofovir. ${ }^{2}$

The most common prescribed protease inhibitor in this study was ritonavir boosted atazanavir $(1.00 \%)$, which was ritonavir boosted lopinavir in previous similar studies. ${ }^{6,21}$ The availability of atazanavir during 2004 was followed by a rapid switch in protease inhibitor prescription patterns, mainly as a result of simplification strategies, in an attempt to ameliorate lipid abnormalities and reduce the pill burden in the world.

Usage of tenofovir (12.54\%) and efavirenz (13.94\%) was higher in comparison to previous similar study. ${ }^{6}$ Tenofovir and efavirenz have convenient dosage schedule. This changing trend of increase usage of tenofovir and efavirenz was also seen in other countries. ${ }^{14,16}$

In this study, antibacterial agents (18.77\%) were the second most common class of drugs prescribed. The most common antibacterial agent used was co-trimoxazole $(10.11 \%)$, followed by antitubercular agents $(8.12 \%)$. These findings are in consonance with other studies. ${ }^{6,17,22}$ Use of co-trimoxazole is justifiable as it is recommended for chemoprophylaxis against Pneumocystis jiroveci infection. ${ }^{5,23}$ Tuberculosis (TB) is the leading opportunistic disease and cause of death in patients with HIV infection. ${ }^{24,25}$ Given the high rates of TB-HIV co-infection, higher usage of antitubercular agents is justifiable.

Like other studies, the third most commonly prescribed drug class in this study was vitamins namely folic acid and vitamin B complex tablets followed by haematinic drugs. ${ }^{6,22}$

The efficacy of antiretroviral therapy in suppressing viral replication and delaying progress of AIDS is related to strict adherence to the treatment. Optimal adherence to the recommended regimes should be $>95 \%$ to avoid development of antiretroviral drug resistance. In this study optimal adherence of $>95 \%$ was achieved in majority of encounters $(90.05 \%)$. These findings are in consonance with findings of other Indian studies. ${ }^{6,26}$ Several factors could explain the good adherence in this study. First, treatment was free of charge for all the patients. Second, good drug procurement and distribution practices in this ART centre avoided disruption of drug supply. Both points have been shown to be a significant cause of drug resistance and ARV failure in Uganda. ${ }^{27}$ Third, this patients were adequately counselled for improving adherence by counsellors in this ART centre. Counselling is an important factor for improving adherence to antiretroviral therapy in HIV positive patients. ${ }^{28}$

Human Immunodeficiency viruses are the initial causative agents in AIDS, but most of the morbidity and mortality in AIDS cases result from opportunistic infections. In this study, among all opportunistic infections, tuberculosis $(59.33 \%)$ was found to be the most common opportunistic infection, followed by upper respiratory tract infections $(16.67 \%)$ and fungal infections $(11.33 \%)$. The findings are in consonance with similar study. ${ }^{6}$ Majority of studies from India and other countries have found tuberculosis to be the most common opportunistic infection among people with HIV infection. ${ }^{24,25}$ Understanding HIV-TB co-infection is of great importance because of increasing prevalence of co-infection, severity of clinical presentation of TB in HIV-positive patients, rapid progression of HIV disease in TB patients and challenges in treatment of co-infected patients due to drug interactions and immune reconstitution syndrome.

The average number of drugs in a prescription is an important indicator for the standard of prescribing. As per the world medicines situation by WHO, the average number of drugs per prescription was 2.39. The study of prescribing pattern in OPD in tertiary care teaching hospital conducted in central India showed 2.38 drugs per prescription. ${ }^{29}$ The average number of drugs per encounter was 3.96 in this study with range of number of drugs prescribed was 1 to 12 . The results are in accordance with the similar study, in which average number of drugs per encounter was $4.26 .^{6}$ The average number of drugs in a prescription in this study was higher than that as per the world medicines situation by the WHO. ${ }^{30}$ The higher average in prescriptions of HIV positive patients is not surprising as multidrug treatment for HIV/AIDS is recommended approach. Also HIV infection is associated with various opportunistic infections. So poly-pharmacy is quite relevant. $^{31}$

Most of the drugs were prescribed in oral formulation. Only $0.81 \%$ drugs were prescribed in injection formulation and $0.37 \%$ was for topical use. Previous study showed similar findings. ${ }^{6}$ The study of prescribing pattern at OPD in tertiary care teaching hospital conducted in central India showed 5\% drugs prescribed were in injection formulation. This is a far below and favourable figure in comparison to that set forth by WHO in this concern i.e. $<10 \% .{ }^{29}$ In this study, $89.85 \%$ drugs were prescribed by generic name and $10.15 \%$ drugs were prescribed by brand names. Among all the prescribed drugs only tablet cotrimoxazole and injection neurobion were prescribed by brand name. The drugs prescribed from National List of 
Essential Medicines 2015 were $90.91 \% .{ }^{32}$ It points towards rational prescription practices. Use of drugs from the essential drug list should be promoted for optimal use of limited financial resources, to have acceptable safety and to satisfy the health needs of the majority of the population. ${ }^{33}$

\section{ACKNOWLEDGEMENTS}

Authors would like to thank to all staff members of ART Centre, G. G. G. Hospital for their cooperation for successful completion of study.

\section{Funding: No funding sources}

Conflict of interest: None declared

Ethical approval: The study was approved by the Institutional Ethics Committee

\section{REFERENCES}

1. UNAIDS. UNAIDS factsheet, 2017. Available at: http://www.unaids.org/sites/default/files/media_asset/ UNAIDS_FactSheet_en.pdf. Accessed 01 November 2017.

2. Flexner C. Antiretroviral agents and treatment of HIV Infection. In: Burton LL, ed. Goodman and Gillman's The Pharmacological Basis of Therapeutics. $12^{\text {th }} \mathrm{Ed}$. New York, NY: McGraw-Hill; 2011:1623-1664.

3. National AIDS Control Organization. NACO annual report 2016-17, 2017. Available at: http://naco.gov.in/sites/default/files/NACO\%20ANN UAL\%20REPORT\%202016-17.pdf. Accessed 01 November 2017.

4. World Health Organization. Introduction to Drug Utilization Research. Geneva: World health organization; 2003.

5. National AIDS Control Organisation. Antiretroviral Therapy Guidelines for HIV-Infected Adults and Adolescents: May 2013. New Delhi: Ministry of Health and Family Welfare Government of India; 2013.

6. Jiyo C, Suthar SD, Dholaria NK, Chavda DA, Bhansali NB, Gosai TR, et al. Drug utilization study of HIV positive patients registered with antiretroviral therapy centre of a tertiary care hospital. J Clin Exp Res. 2013;1(1):12-9.

7. Prakash-Raju GJK, Chowta MN, Rather ZA, Mubeen F. The Pattern of the Initial Anti-retroviral Drug Regimes in HIV Patients at a Tertiary Care Hospital. J Clin Diagn Res. 2012;6(7):1178-80.

8. Hasabi IS, Shivashankarappa AB, Kachapur C, Kaulgud RS. A Study of Compliance to Antiretroviral Therapy among HIV Infected Patients at a Tertiary Care Hospital in North Karnataka. J Clin Diagn Res. 2016 May;10(5):27-31.

9. Patrikar S, Subramaniam S, Vasudevan B, Bhatti V, Kotwal A, Basannar D, et al. AIDS \& Clinical Profile of HIV Patients on Second Line Antiretroviral Therapy: The Indian Experience. J AIDS Clin Res. 2015;6(5):1-5.
10. National AIDS Control Organization. Antiretroviral Therapy Guidelines for HIV-Infected Adults and Adolescents Including Post-Exposure Prophylaxis May 2007. New Delhi: Ministry of Health and Family Welfare Government of India; 2007.

11. Mocroft A, Johnson MA, Philips AN. Factors affecting survival in patients with acquired immune deficiency syndrome. AIDS. 1996;10:1057-65.

12. Obirikorang C, Selleh PK, Abledu JK, Fofie CO. Predictors of Adherence to Antiretroviral Therapy among HIV/AIDS Patients in the Upper West Region of Ghana. ISRN AIDS. 2013;2013:1-7.

13. World Health Organization. Antiretroviral therapy for HIV infection in adults and adolescents: recommendations for a public health approach - 2010 rev. Geneva: World Health Organization; 2010.

14. Duber HC, Dansereau E, Masters SH, Achan J, Burstein R, DeCenso B, et al. Uptake of WHO recommendations for first-line antiretroviral therapy in Kenya, Uganda, and Zambia. PLoS One. 2015;10:112.

15. World Health Organization. Antiretroviral Therapy for HIV Infection in Adults and Adolescents: Recommendations for a public health approach. Geneva: World Health Organization; 2006.

16. Jiménez-Nácher I, García B, Barreiro P, RodriguezNovoa S, Morello J, González-Lahoz J, et al. Trends in the prescription of antiretroviral drugs and impact on plasma HIV-RNA measurements. J Antimicrob Chemother. 2008;62:816-22.

17. Oreagba IA, Usman SO, Akanmu S. Antiretrovirals and Co-Prescribed Drugs for People Living With HIV/AIDS in a University Teaching Hospital, South West Nigeria. Value Heal. 2016;19:A212-3.

18. Easterbrook P, Phillips A, Hill T, Matthias R, Fisher M, Gazzard B, et al. Patterns and predictors of the use of different antiretroviral drug regimens at treatment initiation in the UK. HIV Med. 2008;9:47-56.

19. Ribeiro FA, Tupinambás U, Fonseca MO, Greco DB. Durability of the first combined antiretroviral regime in patients with AIDS at a reference center in Belo Horizonte, Brazil, from 1996 to 2005. Brazilian J Infect Dis. 2012;16(1):27-33.

20. Sapkota S, Shakya R, Pandey B. Study on Highly Active Anti Retroviral Therapy: prescription pattern and side effects. JNPA. 2012;26(1):12-8.

21. Ghani AC, Donnelly CA, Anderson RM. Patterns of antiretroviral use in the United States of America: Analysis of three observational databases. HIV Med. 2003;4:24-32.

22. Fogelman I, Lim L, Bassett R, Volberding P, Fischl MA, Stanley K, et al. Prevalence and Patterns of Use of Concomitant Medications Among Participants in Three Multicenter Human Immunodeficiency Virus Type I Clinical Trials. J Acquir Immune Defic Syndr. 1994 October;7(10):1057-63.

23. National AIDS Control Organization. Guidelines for Prevention and Management of Common Opportunistic Infections/Malignancies among HIVInfected Adult and Adolescent. New Delhi: Ministry 
of Health and Family Welfare Government of India; 2007.

24. Giri PA, Deshpande JD, Phalke DB. Prevalence of pulmonary tuberculosis among HIV positive patients attending antiretroviral therapy clinic. $\mathrm{N}$ Am J Med Sci. 2013;5:367-70.

25. Trinh QM, Nguyen HL, Nguyen VN, Nguyen TVA, Sintchenko V, Marais BJ. Tuberculosis and HIV coinfection-focus on the Asia-Pacific region. Int J Infect Dis. 2015;32:170-8.

26. Sarna A, Pujari S, Sengar AK, Garg R, Gupta I, Dam J. Adherence to antiretroviral therapy \& its determinants amongst HIV patients in India. Indian $\mathbf{J}$ Med Res. 2008;127:28-36.

27. Oyugi JH, Byakika-Tusiime J, Ragland K, Laeyendecker O, Mugerwa R, Kityo C, et al. Treatment interruptions predict resistance in HIVpositive individuals purchasing fixed-dose combination antiretroviral therapy in Kampala, Uganda. AIDS. 2007 May;21(8):965-71.

28. Marchand C, Himmich H, Maaroufi A, Sohier N, Chambon JF, Gagnayre R. Implementation and assessment of an HIV treatment training program (2000-2001) for patients in Casablanca (Morocco), Sante. 2005; 15:73-80.

29. Tatkare SN, Tatkare N, Giri K, Totade S. Analysis of Prescribing Trends at Tertiary Care Teaching Hospital of central India. European Journal of Pharmaceutical and Medical Research. 2016;3(3):463-9.

30. World Health Organization. The World Medicines Situation. Geneva: World Health Organization; 2004.

31. Clay PG. Actual medication pill burden and dosing frequency in HIV-infected patients with undetectable viral loads. J Int Assoc Physicians in AIDS Care (Chic). 2004;3(2):49-55.

32. Ministry of Health and Family Welfare Government of India. National List of Essential Medicines, 2015 Available

at: http://cdsco.nic.in/WriteReadData/NLEM2015/NLEM,\%202015.pdf. Accessed 20 October 2016.

33. World health organization. WHO Policy Perspectives on Medicines- Continuity and Change-Implementing the third WHO Medicines Strategy 2008-2013. Geneva: World health organization; 2010.

Cite this article as: Parmar SP, Sharma JK, Trivedi HR. A study of utilization pattern of drugs in HIV positive patients at antiretroviral therapy centre of a tertiary care teaching hospital. Int J Basic Clin Pharmacol 2018;7:465-72. 